\title{
Estimating population food and nutrient exposure: a comparison of store survey data with household panel food purchases
}

\author{
Helen Eyles ${ }^{1 *}$, Bruce Neal $^{2}$, Yannan Jiang ${ }^{3}$ and Cliona Ni Mhurchu ${ }^{3}$ \\ ${ }^{1}$ National Institute for Health Innovation and Epidemiology and Biostatistics, The University of Auckland, Private Bag 92019, \\ Auckland 1142, New Zealand \\ ${ }^{2}$ George Institute for Global Health, University of Sydney, PO Box M201, Missiden Road, Sydney, NSW 2050, Australia \\ ${ }^{3}$ National Institute for Health Innovation, The University of Auckland, Private Bag 92019, Auckland 1142, New Zealand \\ (Submitted 7 August 2015 - Final revision received 17 November 2015 - Accepted 22 January 2016)
}

\begin{abstract}
Population exposure to food and nutrients can be estimated from household food purchases, but store surveys of foods and their composition are more available, less costly and might provide similar information. Our aim was to compare estimates of nutrient exposure from a store survey of packaged food with those from household panel food purchases. A cross-sectional store survey of all packaged foods for sale in two major supermarkets was undertaken in Auckland, New Zealand, between February and May 2012. Longitudinal household food purchase data (November 2011 to October 2012) were obtained from the nationally representative, population-weighted New Zealand Nielsen HomeScan ${ }^{\circledR}$ panel. Data on 8440 packaged food and non-alcoholic beverage products were collected in the store survey. Food purchase data were available for 1229 households and 16812 products. Store survey data alone produced higher estimates of exposure to Na and sugar compared with estimates from household panel food purchases. The estimated mean difference in exposure to Na was 94 (95\% CI 72,115$) \mathrm{mg} / 100 \mathrm{~g}$ (20\% relative difference; $P<0 \cdot 01)$, to sugar $1.6(95 \% \mathrm{CI} 0 \cdot 8,2 \cdot 5) \mathrm{g} / 100 \mathrm{~g}(11 \% ; P<0 \cdot 01)$, to SFA $-0 \cdot 3(95 \% \mathrm{CI}-0 \cdot 8,0 \cdot 3) \mathrm{g} / 100 \mathrm{~g}(6 \% ; P=0 \cdot 3)$ and to energy $-18(-71,35) \mathrm{kJ} / 100 \mathrm{~g}(2 \% ; P=0.51)$. Compared with household panel food purchases, store survey data provided a reasonable estimate of average population exposure to key nutrients from packaged foods. However, caution should be exercised in using such data to estimate population exposure to $\mathrm{Na}$ and sugar and in generalising these findings to other countries, as well as over time.
\end{abstract}

Key words: Nutrition assessments: Store surveys: Food purchases: Food composition: Population nutrition monitoring: Packaged foods: New Zealand

Diet plays a key role in the prevention and control of premature mortality from non-communicable diseases $(\mathrm{NCD})^{(1)}$. Excess dietary intake of energy and adverse nutrients including $\mathrm{Na}$, SFA and sugar and low intake of beneficial nutrients such as fibre, protein and fruit and vegetables are key risk factors for obesity and other $\mathrm{NCD}^{(2)}$.

In high-income countries, the majority of household food expenditure occurs at supermarkets and convenience stores ${ }^{(3-5)}$, and packaged foods account for most (up to $77 \%$ ) of the energy and nutrients purchased ${ }^{(6,7)}$. Therefore, tracking the packaged food supply may offer an opportunity to monitor population $\operatorname{diets}^{(8)}$. Reformulation programmes are currently gaining increasing attention globally, especially with respect to Na reduction ${ }^{(9,10)}$, and consumer-friendly food labelling is also becoming more of a focus $^{(11)}$. However, country-specific monitoring is vital to assess the impact of such interventions and policies.

Population diets are usually assessed via national surveys using traditional dietary assessment methods such as food records and 24-h dietary recalls. However, these surveys are typically carried out infrequently, are costly and are prone to bias and measurement error due to reliance on selfreporting $^{(12,13)}$. An alternative approach is to use information on national food purchasing patterns obtained from food balance sheets, household economic surveys, till receipts, store surveys and household food purchasing data ${ }^{(14)}$.

Food balance sheets provide information on the per capita supply of fresh and packaged food items available for consumption in a given country over a given time period. The Food and Agriculture Organization of the United Nations ${ }^{(15)}$ collects food balance sheet data for many countries, and these data are an accepted measure of food and nutrient exposure at the country level. Food balance sheet data are useful for assessing trends, but the data are generally aggregated into broad food groups, making them less useful for assessing nutrient exposure from specific food groups. In addition, nutrient composition is generic, and per capita values can be over-inflated because of use of food for feeding livestock ${ }^{(15)}$.

Household economic surveys, till receipts and electronic food purchasing data can also be used to assess trends and only reflect food that is purchased for human consumption. 
Although food purchase data are usually collected at the household rather than the individual level, they are a moderately good proxy for food and nutrient intakes ${ }^{(16,17)}$. Moreover, the objective nature of food purchase data means that they are less affected by reporting biases ${ }^{(18)}$. Food purchase data can also be linked with information on the nutrient composition of foods from store surveys, making it possible to assess availability and population exposure to foods and nutrients; such data also provide a way of objectively monitoring population nutrition over time in response to changes in the food supply and nutrition policy. The acceptability of food purchase data for assessing population exposure to foods and nutrients has been illustrated in the USA, where such data were recently used to independently evaluate reformulation commitments by Walmart ${ }^{(19)}$ and the Healthy Weight Commitment Foundation Pledge (a commitment made by US food companies to reduce the energy content in the food supply) ${ }^{(20)}$. Further, in New Zealand, store survey and food purchase data have previously been linked and show good agreement with self-reported intake data with regard to food groups contributing most to nutrient exposure ${ }^{(21)}$.

Nonetheless, a key problem is that food purchase data are costly, and often do not include food composition information; as such, they are difficult to access and use efficiently, especially for government agencies and university researchers. An increasing number of countries are undertaking store surveys of food and nutrient availability, particularly since the formation of the International Network for Food and Obesity/ non-communicable diseases Research, Monitoring and Action Support (INFORMAS) ${ }^{(22)}$. Store surveys are relatively easy to perform and may be used as a substitute for measuring food availability and exposure to dietary nutrients in the absence of household food purchasing data. However, to the best of our knowledge, there have been no formal statistical comparisons of how store survey data alone compare with household panel food purchases.

Our aim was to compare estimates of average population nutrient exposure from packaged foods based on store survey data alone and household panel food purchase data. The primary objective was to compare the mean $\mathrm{Na}$, SFA, sugar and energy content of the packaged food supply as estimated from store surveys with means from household panel food purchase data. Findings for individual food groups were also evaluated. We hypothesised that exposure estimates based upon store survey data alone would be similar to those estimated from household panel food purchase data.

\section{Methods}

\section{Data sources}

Store survey data. Since 2011, we have undertaken annual cross-sectional surveys of food availability and nutrient content of the New Zealand food supply and recorded them in the Nutritrack database ${ }^{(23)}$. Data are collected by trained fieldworkers who take photographs of the packages of food products on sale in large Auckland supermarkets using a specially developed smartphone application. Supermarkets chosen for data collection represent the biggest retail brands of the two main national supermarket retailers - Foodstuffs $(54 \%$ grocery market share) and Progressive Enterprises (38\% market share $)^{(24)}$, and specific stores are selected based on size and to provide the largest product range possible. Data from photographs are transcribed into a bespoke online searchable database. Products are classified into sixteen food groups used by INFORMAS ${ }^{(25)}$. The 2012 Nutritrack database was used for this analysis; data were collected from two large stores between February and May (from 2013 onwards, Nutritrack data were collected from four large Auckland stores). Christmas shelf-stable products, infant formula, baby foods and sports supplements were excluded because these products were not considered major contributors to dietary intakes ${ }^{(26)}$. The following were also excluded because it is not mandatory in New Zealand for these products to display a Nutrition Information Panel: alcohol, fresh meat and poultry, freshly prepared meals and snacks, fresh fruit and vegetables, plain tea and coffee, and herbs and spices (including salt) ${ }^{(27)}$. The final data set comprised 8440 unique packaged foods and non-alcoholic beverages.

Household food purchasing data. As this analysis involved use of secondary data, ethics approval was not required; 12 months of electronic household food purchasing data for the year to October 2012 were obtained from the New Zealand Nielsen Homescan ${ }^{\circledR}$ panel - a nationally representative consumer panel of approximately 2500 households whose members scan all grocery items brought into the home for consumption. Households in the Homescan ${ }^{\circledR}$ panel are recruited to match the New Zealand population in terms of region, life stage group and household size and are weighted by these factors using the most recent New Zealand Census $(2006)^{(28)}$. Only households that had completed large weekly shops and had been in the panel for 6 months or longer (1229 projected to the New Zealand population of 1.2 million households) ${ }^{(28)}$ were included. Nielsen Homescan ${ }^{\circledR}$ data do not include nutrient information. The initial data set included 27347 unique food and beverage products with 1230311000 units sold for the value of NZ\$4339639000.

To prepare household food purchasing data for analysis, food categories that were excluded from the store survey data (above) were also removed from the Homescan ${ }^{\circledR}$ food purchasing data set. In total, 484 products were removed because they could not be matched with relevant nutrient data. Products were then ranked by purchase volumes and the bottom $5 \%$ of sales was removed for feasibility purposes. The final data set included 16812 unique food and beverage products with 1153109000 total units sold for the value of NZ\$3738229000 ( $85 \%$ of sales from the initial data set).

\section{Categorisation of food products}

Products from the store survey and Homescan ${ }^{\circledR}$ food purchasing data sets were assigned a food group using the INFORMAS and Global Food Monitoring Group categorisation system (including sixteen food groups at the highest level) ${ }^{(25)}$. 


\section{Matching food purchases with store surveys}

Nutrient composition information for each purchased food and beverage product in the Homescan ${ }^{\circledR}$ household food purchasing data was obtained by matching with a corresponding product from the store survey data. Matching was undertaken using barcode in the first instance. Where products could not be matched, approximate string matching (finding patterns in the data using product and brand name and package size) was undertaken using Oracle database software. Finally, products in the Homescan ${ }^{\circledR}$ data set that could not be directly matched with a product from the store survey were allocated the average (mean) nutrient profile of their allocated food category. Of the 16812 unique packaged food and beverage products in the final data set, 7707 had brand-specific food composition data and the remaining 9105 had the mean nutrient profile of their food category.

\section{Outcomes}

The primary outcome of interest was the mean estimates of $\mathrm{Na}$, SFA, sugar and energy in packaged foods and beverages, which were compared between the store survey data and the household panel food purchase data.

\section{Statistical analysis}

Store survey data were weighted by sales from the household food purchasing data. The weighted estimates were calculated by multiplying the nutrient content for each unique food product by the number of units purchased, summing the resulting values for all foods and then dividing the sum by the total units purchased. Average values of $\mathrm{Na}$, SFA, sugar and energy were estimated by summing the nutrient data across all items in each database and dividing by the number of items.

Paired $t$ tests were used to determine whether there were significant differences between the estimates obtained from the store survey data alone and the household panel food purchase data. Parametric tests were deemed appropriate for our analysis assuming the central limit theorem, which suggests we should apply the normal-distribution theory for means from large sample sizes even when the original distribution is not normal $^{(29,30)}$. Statistical tests were two-sided at the $5 \%$ significance level. As both absolute and relative (\%) differences in means were deemed important, both metrics were plotted alongside one another on bar graphs to provide a visual comparison of estimates from store survey data $v$. from household panel food purchasing data.

Data were maintained and processed in Microsoft Excel 2010. Statistical analyses were carried out using IBM SPSS Statistics (version 21.0).

\section{Results}

\section{Estimated population exposure to sodium}

The mean $\mathrm{Na}$ content of packaged food and non-alcoholic beverage products derived from the store survey in 2012 was $465 \mathrm{mg} / 100 \mathrm{~g}$ (online Supplementary Table S1). The corresponding mean value estimated by weighting store survey data using household food purchase data was $371 \mathrm{mg} / 100 \mathrm{~g}$. The absolute

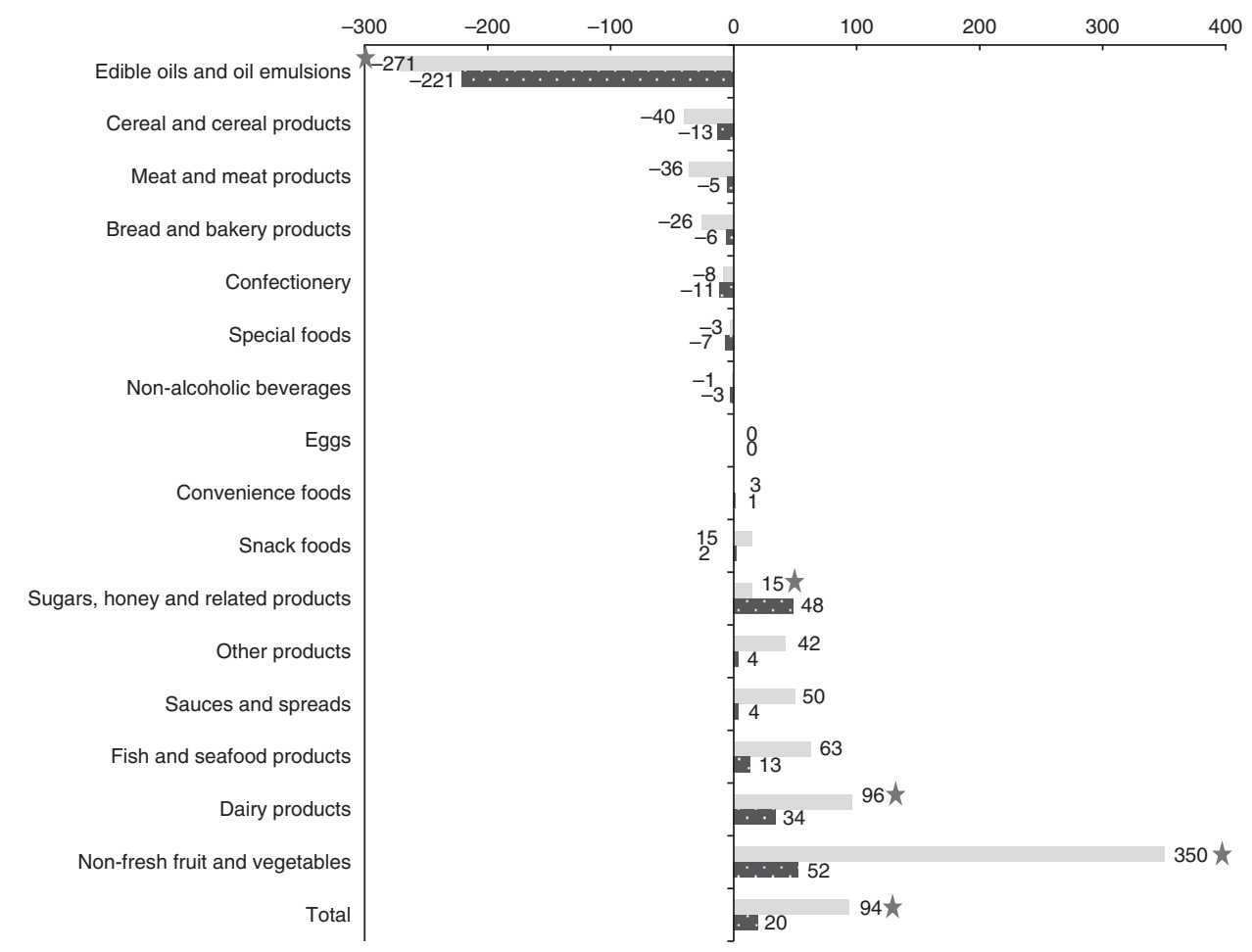

Fig. 1. Absolute and relative mean differences in exposure to sodium using New Zealand store survey and food purchasing data (2011/2012). $\star$, Significance testing only on overall absolute mean differences $(P<0.05)$. $\square$, Absolute difference (survey-weighted, mg/100g); $\square$, relative difference (survey-weighted, \%). 


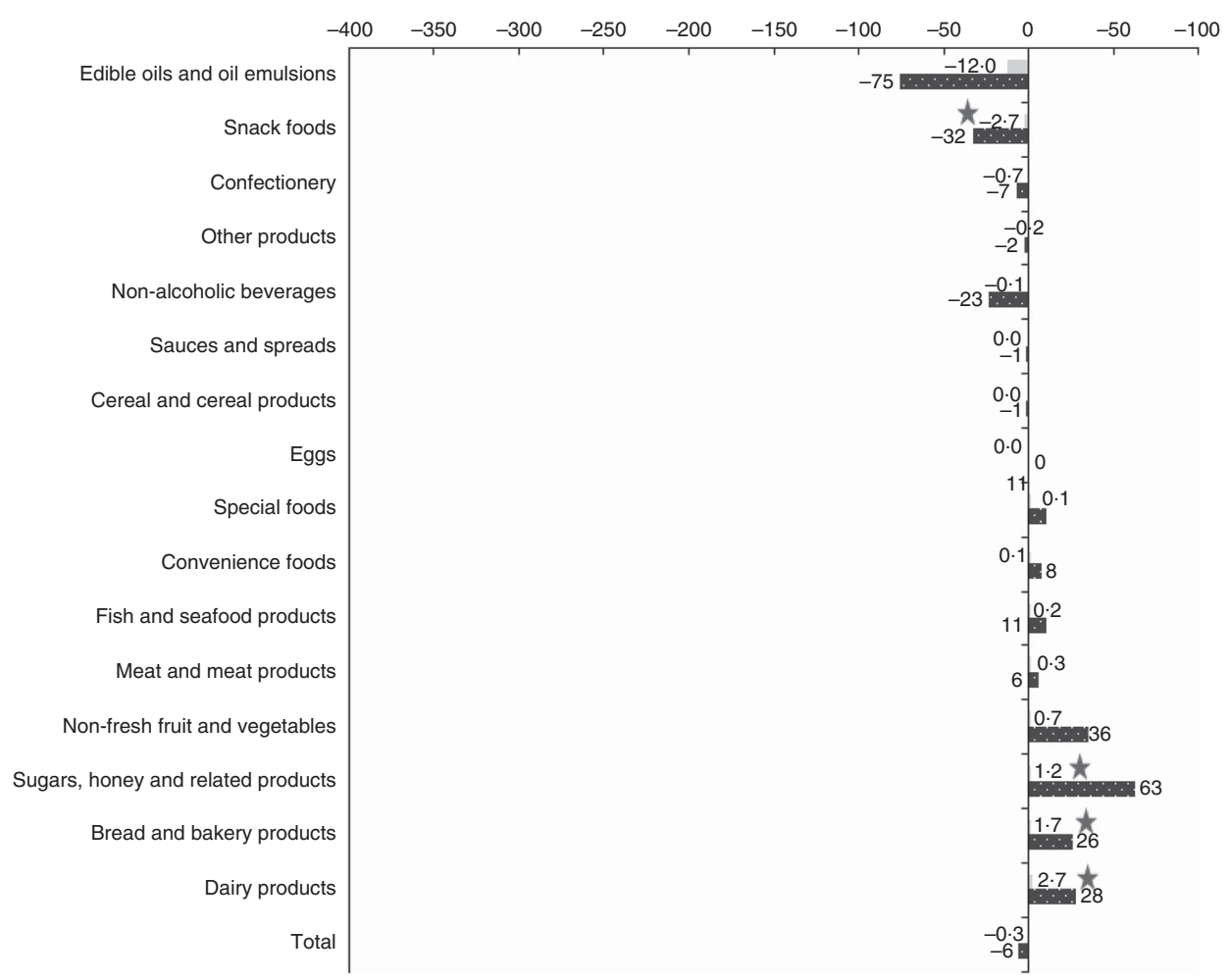

Fig. 2. Absolute and relative mean differences in exposure to SFA using New Zealand store survey and food purchasing data (2011/2012). $\star$, Significance testing only on absolute mean differences $(P<0.05)$. $\square$, Absolute difference (survey-weighted, $\mathrm{g} / 100 \mathrm{~g})$; $\square$, relative difference (survey-weighted, \%).

mean difference was 94 (95\% CI 72, 115) mg/100g such that the store survey data resulted in a $20 \%$ higher estimate $(P<0 \cdot 01)$.

Compared with the estimates from household food purchases, four food groups had significantly different estimates of exposure using store survey data alone: dairy products, edible oils and emulsions, non-fresh fruit and vegetables, and sugars, honey and related products (all $P<0 \cdot 01$ ). The absolute mean difference ranged from $-271(95 \% \mathrm{CI}-435,-107) \mathrm{mg} /$ $100 \mathrm{~g}$ for edible oils and emulsions to 350 (95\% CI 289, 411) $\mathrm{mg} / 100 \mathrm{~g}$ for non-fresh fruit and vegetables. Relative differences were particularly large for non-fresh fruit and vegetables, edible oils and emulsions, and dairy products (Fig. 1).

\section{Estimated population exposure to SFA}

The mean estimate of SFA from store survey data alone and that from household panel food purchase data was 4.8 and $5 \cdot 1 \mathrm{~g} / 100 \mathrm{~g}$, respectively (online Supplementary Table S2). There was no detectable difference in means (mean difference $=-0 \cdot 3(95 \% \mathrm{CI}-0 \cdot 8,0 \cdot 3) \mathrm{g} / 100 \mathrm{~g} ; P=0 \cdot 3)$.

Compared with the estimates from household food purchases, four food groups had significantly different estimates of exposure using store survey data alone: bread and bakery products, dairy products, snack foods, and sugars, honey and related products (all $P<0 \cdot 01$ ). The absolute mean difference ranged from $-2 \cdot 7(95 \% \mathrm{CI}-4 \cdot 7,-0 \cdot 7) \mathrm{g} / 100 \mathrm{~g}$ for snack foods to $2 \cdot 7(95 \%$ CI $1 \cdot 8,3 \cdot 5) \mathrm{g} / 100 \mathrm{~g}$ for dairy products. No food groups had significant absolute and particularly large relative mean differences (Fig. 2).

\section{Estimated population exposure to sugar}

The mean estimate of sugar from store survey data alone and that from household food purchase data was 15.2 and $13.5 \mathrm{~g} / 100 \mathrm{~g}$, respectively (online Supplementary Table S3). The absolute difference in means was 1.6 (95\% CI 0.8, 2.5) g/100 g such that the store survey data resulted in an $11 \%$ higher estimate of exposure $(P<0 \cdot 01)$.

Compared with the estimates from household food purchases, six food groups had significantly different estimates of exposure using store survey data alone: bread and bakery products, dairy products, edible oils and emulsions, non-fresh fruit and vegetables, sugars, honey and related products, and snack foods (all $P<0 \cdot 01$ ). The absolute mean difference ranged from $-0.5(95 \% \mathrm{CI}-0.7,-0.2) \mathrm{g} / 100 \mathrm{~g}$ for edible oils and emulsions to $5 \cdot 3(95 \%$ CI $3 \cdot 7,7 \cdot 0) \mathrm{g} / 100 \mathrm{~g}$ for bread and bakery products. The only food group with a particularly large relative mean difference was bread and bakery products (Fig. 3).

\section{Estimated population exposure to energy}

The mean estimate of energy from store survey alone and household food purchase data was 1081 and $1099 \mathrm{~kJ} / 100 \mathrm{~g}$, respectively (online Supplementary Table S4). There was no difference in means: mean difference $=-18$ (95\% CI -71 , $35) \mathrm{kJ} / 100 \mathrm{~g}$. 


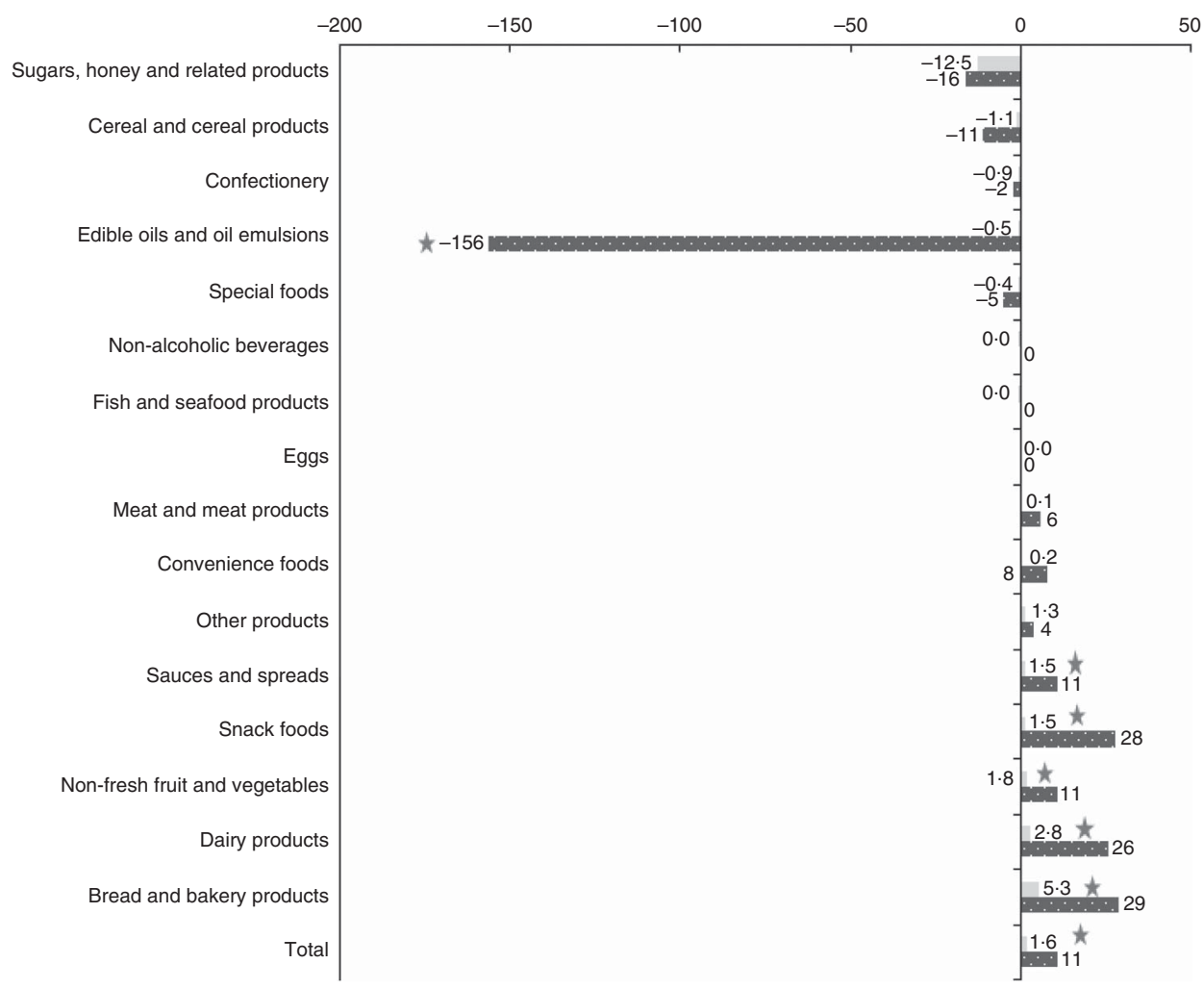

Fig. 3. Absolute and relative mean differences in exposure to sugar using New Zealand store survey and food purchasing data (2011/2012). $\star$, Significance testing only on absolute mean differences $(P<0.05)$. $\square$, Absolute difference (survey-weighted, g/100g); $\square$, relative difference (survey-weighted, \%).

Compared with the estimates from household food purchases, four food groups had significantly different estimates using store survey data alone: bread and bakery products, convenience foods, dairy products, and non-fresh fruit and vegetables (all $P<0 \cdot 05$ ). The absolute mean difference ranged from 59 (95\% CI 5, 114) kJ/100 g for Convenience foods to 262 (95\% CI 200, 324) kJ/100 g for dairy products. Relative differences were particularly large for convenience foods, dairy products, and non-fresh fruit and vegetables (Fig. 4).

\section{Discussion}

We found that cross-sectional store survey data may be a useful tool for estimating population exposure to dietary SFA and energy in the absence of household food purchase data. However, caution should be applied when using store survey data alone in estimating exposure to $\mathrm{Na}$ and sugar, because the results for these nutrients were significantly different between the two methods. This appeared to result from specific food groups being highly discrepant: bread and bakery products, dairy products, edible oils and emulsions, and non-fresh fruit and vegetables.

There are several strengths to these analyses, including that store survey data were collected using a systematic, robust method from all packaged food and beverage products on sale at two large stores representing the major supermarket chains in
New Zealand. As such, these data are likely to represent the majority of packaged food and beverage products purchased by New Zealand households. Household panel food purchase data were based on a large combined data set of $>17000$ packaged food and beverage products, and the data were representative of the New Zealand population. Nonetheless, including more stores in our survey would have increased the matching rate between Nutritrack (store survey) and food purchasing data. Furthermore, our analyses omitted fresh foods as well as foods and beverages consumed away from home. Fresh foods are estimated to account for approximately $10 \%$ of the supermarket food supply by product number ${ }^{(16)}$ and $25 \%$ by sales ${ }^{(3)}$; their exclusion may have resulted in an overestimate of exposure to $\mathrm{Na}$, sugar and energy-density values by both our measurement methods, because these nutrients are not generally as concentrated in fresh foods as in packaged foods ${ }^{(31)}$. However, inclusion of fresh meats (in the absence of fresh fruit and vegetables) may have increased the estimate of exposure to SFA, because fresh meat is a major contributor to SFA intakes in New Zealand ${ }^{(32)}$. Foods and beverages consumed away from home are estimated to account for approximately one-quarter of all foods and beverages consumed by New Zealand households by expenditure ${ }^{(3)}$. As restaurant and takeaway foods and beverages are often high in Na, SFA, sugar and energy $^{(33)}$, exclusion of these products may have underestimated exposure for all nutrients. Nonetheless, store survey data and household food purchase data may be useful tools for 


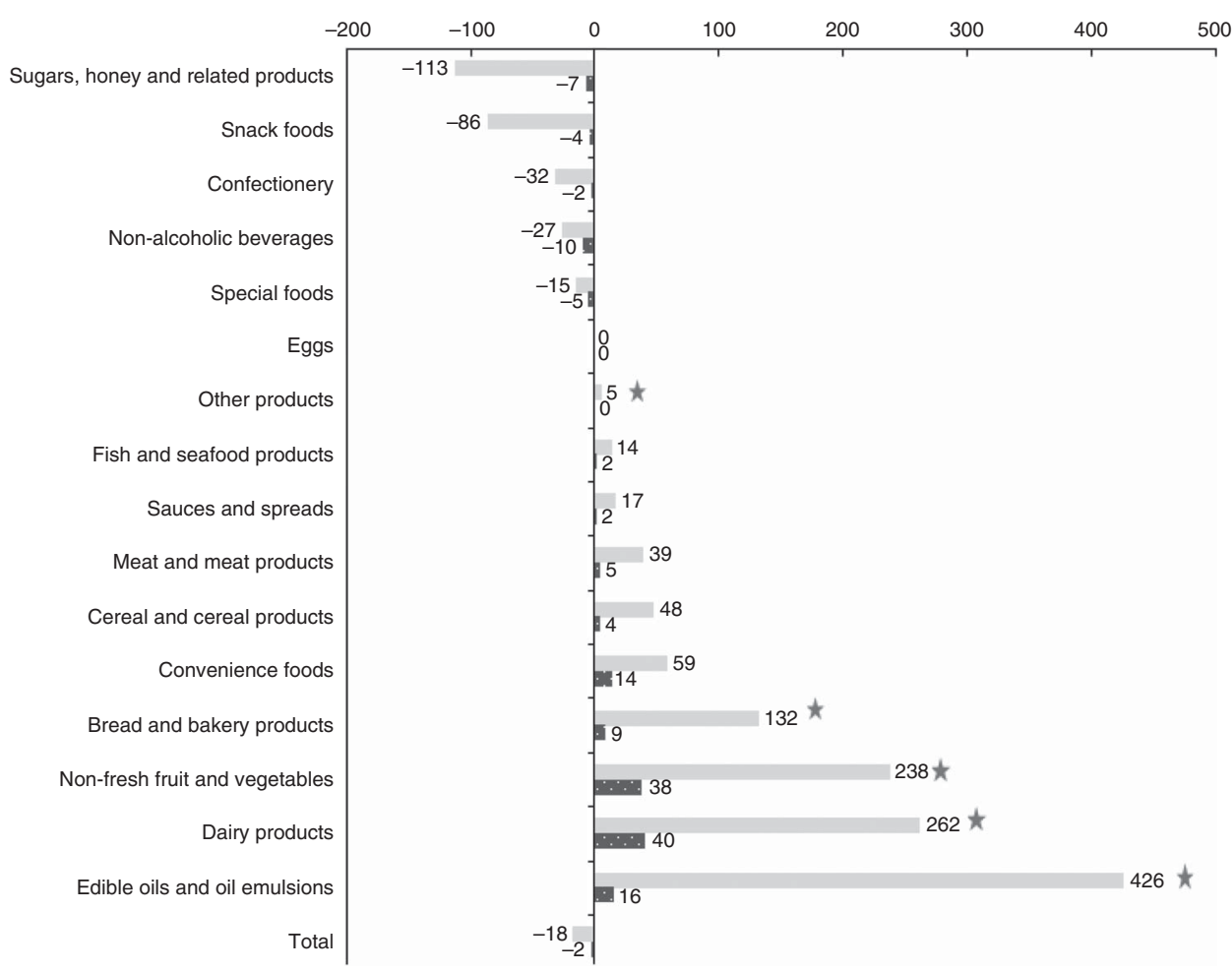

Fig. 4. Absolute and relative mean differences in exposure to energy using New Zealand store survey and food purchasing data (2011/2012). $\star$, Significance testing only on absolute mean differences $(P<0.05)$. $\square$, Absolute difference (survey-weighted, $\mathrm{kJ} / 100 \mathrm{~g}$ ); $\square$, relative difference (survey-weighted, \%).

measuring exposure to packaged foods and nutrients over time, especially if their contribution to population diets remains constant. Finally, table salt was omitted from the current analyses - inclusion would have increased estimated population exposure to $\mathrm{Na}$.

Nielsen HomeScan data account for $75 \%$ of food sales in New Zealand by expenditure (Nielsen Company, personal communication), and a number of food categories were excluded from our analyses, such as, alcohol, plain tea and coffee, herbs and spices, and special purpose foods not displaying nutrition information on their package, 484 products that could not be matched with nutrient data, and the bottom $5 \%$ of sales. Nonetheless, given the representative nature of the HomeScan panel and the fact that the present analysis was based on means, it is unlikely that the $25 \%$ of missing sales would substantially change the present findings. Further, the food categories excluded from the analyses would be unlikely to contribute substantially to annual nutrient and energy purchases. Finally, the food purchasing data used in these analyses were for 1 year and further work needs to be carried out to see whether they hold true over time.

A 2007 systematic review assessing the feasibility and availability of store sales data supported their use for monitoring population food and nutrient intakes as an adjunct to traditional dietary assessment methods ${ }^{(14)}$. More recently, food purchasing data either in electronic format or from supermarket till receipts have been used to monitor population exposure to $\mathrm{Na}$ in the UK, USA and New Zealand food supplies ${ }^{(21,34,35)}$, to assess the impact of the UK Na reduction strategy ${ }^{(36)}$, to calculate the energy density of the Scottish diet and monitor progress towards dietary targets $^{(37,38)}$, and to determine the outcomes of supermarketbased intervention studies ${ }^{(39-42)}$. However, none of these studies has specifically evaluated the relative utility of cross-sectional store survey $v$. longitudinal food sales data to monitor population diets.

If one examines the difference in the $\mathrm{Na}$ density estimated from store survey and weighted household food purchase data in New Zealand with the $\mathrm{UK}^{(34)}$, the food groups illustrating the largest differences between store surveys and food purchases are quite different (no overall comparison was provided in the UK study). In our present analyses, we identified non-fresh fruit and vegetables, sugar, honey and related products (including dessert toppings, sweeteners and syrups), dairy products, and edible oils and emulsions (butter, margarine and oils) as having the largest relative differences between store surveys and food purchases (percentage difference in means, 52, 48, 34 and $-221 \%$, respectively). In contrast, when we undertook a simple analysis using UK-provided data to calculate relative differences in means between store survey and household food purchase data, dairy products (191\% difference), bread and bakery products (26\%), cereal and cereal products (16\%), and processed meat (15\%) had the largest relative differences between estimates. These disparities likely reflect different availability of products and food purchasing patterns between countries. The UK Na reduction strategy may have also played a part ${ }^{(36)}$. Similarly, if one examines the energy density from food purchasing data between New Zealand and Scotland ${ }^{(37)}$, a 
large difference is observed (1099v. $718 \mathrm{~kJ} / 100 \mathrm{~g}$, respectively). However, the Scottish study incorporated fresh foods, which if included in the current analysis would have reduced the energy density for New Zealand food purchases. Indeed, the energy density of packaged and fresh food purchases made by supermarket shoppers in the 3-month baseline phase of a large ( $n$ 1104) New Zealand trial was $730 \mathrm{~kJ} / 100 \mathrm{~g}^{(39)}$. Regardless, in both countries, the energy density of the food supply is higher than that recommended for health by the World Cancer Research Fund (525 kJ/100 g excluding drinks) ${ }^{(43)}$

\section{Conclusion}

In conclusion, compared with household food purchasing data, store survey data from packaged foods may provide a reasonable approximation of exposure to dietary SFA and energy. Similar analyses from other countries are needed to determine whether the present findings remain constant across countries, as well as over time. Addition of fresh foods and foods and beverages consumed away from the home would also help provide a more complete picture of population nutrient exposures. In the meantime, caution should be applied in using store survey data to estimate population exposure to $\mathrm{Na}$ and sugar or for purposes other than measurement/monitoring, for example, for consumer education, a focus on foods rather than nutrients is also likely to be most useful ${ }^{(44,45)}$

\section{Acknowledgements}

The authors thank the Nielsen Company for providing sales data from their New Zealand Homescan ${ }^{\circledR}$ panel, Fieldworkers Ashmita Chand and Mark Derksen for collecting data in stores, Michael $\mathrm{Ng}$ and Colleen $\mathrm{Ng}$ for assisting with electronic data linkage and Emma Shields and Rita George for assisting with data linkage.

This work was supported by a Health Research Council of New Zealand programme grant (C. N. M., B. N., H. E.; grant no. 13/724). H. E. was funded by a Heart Foundation of New Zealand research fellowship at the time of writing (grant no. 1463). Bruce Neal is supported by an Australian Research Council Future Fellowship (DP100100295), a National Health and Medical Research Council of Australia Senior Research Fellowship (APP100311) and works within a National Health and Medical Research Council (NHMRC) Centre for Research Excellence for Obesity Policy (APP1041020). The funders had no role in the design, analysis or writing of this article.

H. E., B. N. and C. N. M. contributed to the research question and study design. H. E. led the collection of nutrient data and linkage with sales information, undertook the analysis and drafted the manuscript. Y. J. contributed to the analysis. Y. J., B. N., Y. J. and H. E. contributed to the interpretation of findings. B. N., Y. J. and C. N. M. reviewed the manuscript.

The authors declare that there are no conflicts of interest.

\section{Supplementary material}

For supplementary material/s referred to in this article, please visit http://dx.doi.org/doi:10.1017/S000711451600088X

\section{References}

1. World Health Organization \& Food and Agriculture Organization of the United Nations (2003) Diet, Nutrition and the Prevention of Chronic Diseases: Report of a Joint WHO/FAO Expert Consultation. WHO Technical Report Series. Geneva: WHO. https://www.google.co.nz/search?q=Diet\%2C+nutrition+and+ the+prevention+of+chronic+diseases $\% 3 \mathrm{~A}++$ Report+of+a+joint+ WHO\%2FFAO+expert+consultation\&ie $=$ utf-8\&oe $=$ utf-8\&aq=t\&rls =org.mozilla:en-US:official\&client=firefox-a\&channel=fflb\&gfe_rd $=$ cr\&ei=yLJCVqvHGcbN8Ae21ofoBA (accessed November 2015).

2. Lozano R, Naghavi M, Foreman K, et al. (2012) Global and regional mortality from 235 causes of death for 20 age groups in 1990 and 2010: systematic analysis for the Global Burden of Disease Study 2010. Lancet 380, 2095-2128.

3. Statistics New Zealand (2013) Household Economic Survey: Year Ended June 2013. Wellington: Statistics New Zealand. http:// www.stats.govt.nz/browse_for_stats/people_and_communities/ Households/HouseholdEconomicSurvey_HOTPYeJun13.aspx (accessed August 2015).

4. Office for National Statistics (2014) Living costs and food survey. http://www.ons.gov.uk/ons/rel/family-spending/family-spending/2014-edition/index.html (accessed March 2015).

5. US Bureau of Labor Statistics (2013) Consumer expenditures in 2013. http://www.bls.gov/cex/ (accessed March 2015).

6. Eicher-Miller HA, Fulgoni VL \& Keast DR (2012) Contributions of processed foods to dietary intake in the US from 2003-2008. A report of the Food and Nutrition Science Solutions Joint Taskforce of the Academy of Nutrition and Dietetics, American Society for Nutrition, Institute of Food Technologists, and International Food Information Council. I Nutr, 2065S-2072S.

7. Slimani N, Deharveng G, Southgate DAT, et al. (2009) Contribution of highly industrially processed foods to the nutrient intakes and patterns of middle-aged populations in the European Prospective Investigation into Cancer and Nutrition study. Eur J Clin Nutr 63, Suppl. 4, S206-S225.

8. Ni Mhurchu C \& Lawes C (2005) National food supply: a major opportunity to improve population health. $N Z$ Med J 118, 1750.

9. Zarocostas J (2011) WHO lists "best buys" for cutting deaths from non-communicable disease. BMJ 342, d2648.

10. Webster JL, Trieu K, Dunford E, et al. (2014) Target salt 2025: a global overview of national programs to encourage the food industry to reduce salt in foods. Nutrients $\mathbf{6}$, 3274-3287.

11. European Food Information Council (2014) Global Update on Nutrition Labelling. Brussels: European Food Information Council. http://www.google.co.nz/url?sa=t\&rct=j\&q=\&esrc=s \&source $=$ web $\& c d=1 \& v e d=0 C B w Q F j A A a h U K E w i 1 j d q 4$ tIfJA hUh2KYKHTDwBrM\&url=http\%3A\%2F\%2Fwww.eufic.org\%2 Fupl\%2F1\%2Fdefault\%2Fdoc\%2Fglobalupdateexecsumjan2014 $\%$ 252013\%2520jan\%25202014_finalwebsummary.pdf\&usg=AF QjCNF52gXZjdT1VftzocFvQr8X0jRFIw\&sig2=YCt1bRz6PYiH6mXwJuWMw\&cad=rja (accessed November 2015).

12. Block G (1989) Human dietary assessment: methods and issues. Prev Med 18, 653-660.

13. Gemming L, Jiang Y, Swinburn B, et al. (2014) Underreporting remains a key limitation of self-reported dietary intake: an analysis of the 2008/09 New Zealand adult nutrition survey. Eur J Clin Nutr 68, 259-264. 
14. Tin Tin S, Ni Mhurchu C \& Bullen C (2007) Supermarket sales data feasibility and applicability in food and nutrition monitoring. Nutr Rev 65, 20-30.

15. Food and Agriculture Organization of the United Nations (2014) Food balance sheets. http://faostat3.fao.org/ download/FB/*/E (accessed December 2014).

16. Hamilton S, Mhurchu CN \& Priest P (2007) Food and nutrient availability in New Zealand: an analysis of supermarket sales data. Public Health Nutr 10, 1448-1455.

17. Eyles H, Jiang Y \& Ni Mhurchu C (2010) Use of household supermarket sales data to estimate nutrient intakes: a comparison with repeat 24-hour dietary recalls. J Am Diet Assoc 110 , 106-110.

18. Chesher A (1997) Diet revealed? Semiparametric estimation of nutrient intake-age relationships. $J$ R Statist Soc A 160, 389-428.

19. Mathias KC, Ng SW \& Popkin B (2015) Monitoring changes in the nutritional content of ready-to-eat grain-based dessert products manufactured and purchased between 2005 and 2012. J Acad Nutr Diet 115, 360-368.

20. Ng SW \& Popkin BM (2014) The Healthy Weight Commitment Foundation Pledge. Calories purchased by U.S. households with children, 2000-2012. Am J Prev Med 47, 520-530.

21. Eyles H \& Ni Mhurchu C (2014) Potential for electronic household food purchase data to enhance population nutrition monitoring. $N Z$ Med J 127, 68-71.

22. Swinburn B, Sacks G, Vandevijvere $S$, et al. (2013) INFORMAS (International Network for Food and Obesity/non-communicable diseases Research, Monitoring and Action Support): overview and key principles. Obes Rev 14, 1-12.

23. National Institute for Health Innovation (2013) Nutritrack: reformulation of processed foods to promote health. http:// nihi.auckland.ac.nz/page/current-research/our-nutrition-andphysical-activity-research/nutritrack-reformulation-processe (accessed February 2013).

24. Euromonitor PLC (2014) Passport Global Market Information Database. London: Euromonitor. http://www.euromonitor. com/passport (accessed November 2015).

25. Dunford E, Webster J, Metzler AB, et al. (2011) International collaborative project to compare and monitor the nutritional composition of processed foods. Eur J Prev Cardiol 19, 1326-1332.

26. Ministry of Health, University of Otago (2011) A Focus on Nutrition: Key Findings of the 2008/09 New Zealand Adult Nutrition Survey. Wellington: Ministry of Health. http://www. health.govt.nz/publication/focus-nutrition-key-findings-200809-nz-adult-nutrition-survey (accessed November 2015).

27. Australian Government (2014) Australia New Zealand Food Standards Code-Standard 1.2.1 - application of labelling and other information requirements. http://www.comlaw.gov.au/ Details/F2014C01178/Download (accessed March 2015).

28. Statistics New Zealand (2006) 2006 Census data. http://www. stats.govt.nz/Census/2006CensusHomePage.aspx (accessed October 2011)

29. Wild CJ \& Seber GAF (1999) Chance Encounters: A First Course in Data Analysis and Inference, 1st ed. Hoboken: John Wiley \& Sons Incorporated.

30. Lumley T, Diehr P, Emerson S, et al. (2002) The importance of the normality assumption in large public health data sets. Ann Rev Public Health 23, 151-169.

31. The New Zealand Institute of Plant and Food Research Limited (2011) New Zealand Food Composition Database: The Concise New Zealand Food Composition Tables. Palmerston North: The New Zealand Institute of Plant and Food Research Limited. http://www.foodcomposition.co.nz/concise-tables （accessed February 2012).

32. Ministry of Health (2011) Data and Statistics, Nutrition Survey, 2008/09 Adult Nutrition Survey. http://www.moh.govt.nz/ moh.nsf/indexmh/dataandstatistics-survey-nutrition (accessed August 2011).

33. Devi A, Eyles H, Rayner M, et al. (2014) Nutritional quality, labelling and promotion of breakfast cereals on the NZ market. Appetite, 253-260.

34. Ni Mhurchu C, Capelin C, Dunford EK, et al. (2011) Sodium content of processed foods in the United Kingdom: analysis of 44,000 foods purchased by 21,000 households. Am J Clin Nutr 93, 594-600.

35. Gillespie C, Maalouf J, Yuan K, et al. (2014) Sodium content in major brands of U.S. packaged foods, 2009. Am J Clin Nutr, 344-353.

36. Eyles H, Webster JL, Jebb SA, et al. (2013) Impact of the UK voluntary sodium reduction targets on the sodium content of processed foods from 2006 to 2011: analysis of household consumer panel data. Prev Med 57, 555-560.

37. Barton KL, Wrieden WL, Sherriff A, et al. (2014) Energy density of the Scottish diet estimated from food purchase data: relationship with socio-economic position and dietary targets. Br J Nutr 112, 80-88.

38. Wrieden WL, Armstrong J, Anderson AS, et al. (2014) Choosing the best method to estimate the energy density of a population using food purchase data. J Hum Nutr Diet 28, 126-134.

39. Ni Mhurchu C, Blakely T, Jiang Y, et al. (2010) Effects of price discounts and tailored nutrition education on supermarket purchases: a randomized, controlled trial. Am J Clin Nutr $\mathbf{9 1}$, 736-747.

40. Waterlander WE, de Boer MR, Schuit AJ, et al. (2012) Price discounts significantly enhance fruit and vegetable purchases when combined with nutrition education: a randomized controlled supermarket trial. Am J Clin Nutr 97, 886-895.

41. Ball K, McNaughton SA, Mhurchu CN, et al. (2011) Supermarket Healthy Eating for Life (SHELf): protocol of a randomised controlled trial promoting healthy food and beverage consumption through price reduction and skill-building strategies. BMC Public Health 11, 715.

42. Brimblecombe J, Ferguson M, Liberato SC, et al. (2013) Stores healthy options project in remote indigenous communities (SHOP@RIC): a protocol of a randomised controlled trial promoting healthy food and beverage purchases through price discounts and in-store nutrition education. BMC Public Health 13, 744

43. World Cancer Research Fund \& American Institute for Cancer Research (2007) Food, Nutrition, Physical Activity and the Prevention of Cancer: A Global Perspective: A Project of World Cancer Research Fund International. Washington, DC: American Institute for Cancer Research.

44. Katz DL \& Meller S (2014) Can we say what diet is best for health? Ann Rev Public Health 35, 83-103.

45. Ministry of Health of Brazil, Secretariat of Health Care, Primary Helath Care Department (2014) Dietary guidelines for the Brazilian population. http://www.google.co.nz/url?sa $=\mathrm{t} \& \mathrm{rct}=\mathrm{j} \& \mathrm{q}=\&$ esrc $=\mathrm{s} \&$ source $=$ web $\& \mathrm{~cd}=1 \& \mathrm{ved}=0 \mathrm{CBwQFjA}$ AahUKEwiyp53W9ffIAhUjW6YKHTUuCoc\&url=http\%3A\%2 F\%2Fwww.foodpolitics.com\%2Fwp-content\%2Fuploads\%2F Brazilian-Dietary-Guidelines-2014.pdf\&usg=AFQjCNGnQn z0qTBFpMjeoEKERYZZ5FC2BQ\&sig2=G_RyZmmITF7evie 27_YNLA\&cad=rja (accessed November 2015). 